\title{
Association of red blood cell transfusion and in-hospital mortality in patients admitted to the intensive care unit: a systematic review and meta-analysis
}

Yi Zheng ${ }^{1 \dagger}$, Caihong $\mathrm{Lu}^{2+}$, Shiqing Wei ${ }^{1}, \mathrm{Ye} \mathrm{Li}^{1}$, Lu Long ${ }^{1}$ and Ping Yin ${ }^{1 *}$

\begin{abstract}
Introduction: Previous research has debated whether red blood cell (RBC) transfusion is associated with decreased or increased mortality in patients admitted to the intensive care unit (ICU). We conducted a systematic review and meta-analysis to assess the relationship of RBC transfusion with in-hospital mortality in ICU patients.

Methods: We carried out a literature search on Medline (1950 through May 2013), Web of Science (1986 through May 2013) and Embase (1980 through May 2013). We included all prospective and retrospective studies on the association between RBC transfusion and in-hospital mortality in ICU patients. The relative risk for the overall pooled effects was estimated by random effects model. Sensitivity analyses were conducted to assess potential bias.

Results: The meta-analysis included 28,797 participants from 18 studies. The pooled relative risk for transfused versus nontransfused ICU patients was $1.431(95 \% \mathrm{Cl}, 1.105$ to 1.854). In sensitivity analyses, the pooled relative risk was 1.211 ( $95 \% \mathrm{Cl}, 0.975$ to 1.505$)$ if excluding studies without adjustment for confounders, 1.178 (95\% Cl, 0.937 to 1.481) if excluding studies with relative high risk of bias, and $0.901(95 \% \mathrm{Cl}, 0.622$ to 1.305$)$ if excluding studies without reporting hazard ratio (HR) or relative risk (RR) as an effect size measure. Subgroup analyses revealed increased risks in studies enrolling patients from all ICU admissions (RR 1.513,95\%Cl 1.123 to 2.039), studies without reporting information on leukoreduction (RR $1.851,95 \% \mathrm{Cl} 1.229$ to 2.786 ), studies reporting unadjusted effect estimates (RR 3.933, 95\% 2.107 to 7.343 ), and studies using odds ratio as an effect measure (RR $1.465,95 \% \mathrm{Cl} 1.049$ to 2.045). Meta-regression analyses showed that RBC transfusion could decrease risk of mortality in older patients (slope coefficient $-0.0417,95 \% \mathrm{Cl}-0.0680$ to -0.0154 ).

Conclusions: There is lack of strong evidence to support the notion that ICU patients who receive RBC transfusion have an increased risk of in-hospital death. In studies adjusted for confounders, we found that RBC transfusion does not increase the risk of in-hospital mortality in ICU patients. Type of patient, information on leukoreduction, statistical method, mean age of patient enrolled and publication year of the article may account for the disagreement between previous studies.
\end{abstract}

\footnotetext{
*Correspondence: pingyin2000@126.com

${ }^{\dagger}$ Equal contributors

'Department of Epidemiology and Biostatistics, School of Public Health, Tongji Medical College, Huazhong University of Science and Technology, 1037 Luoyu Road, Hongshan, Wuhan, China

Full list of author information is available at the end of the article
} 


\section{Introduction}

Anemia is highly prevalent among critically ill patients [1]. Nearly $60 \%$ of the patients admitted to intensive care units (ICUs) had a baseline hemoglobin $(\mathrm{Hb})$ level less than $12 \mathrm{~g} / \mathrm{dL}$ and 30\% less than $9 \mathrm{~g} / \mathrm{dL}$ [2-4]. Anemia persisted throughout the duration of their ICU stay and long after ICU discharge [5]. Anemia could lead to a decreased tissue oxygen delivery capacity, and is associated with poor outcomes, including acute myocardial infarction, heart failure, chronic kidney disease and risk of death [6-10].

Transfusion of red blood cells (RBCs) has been one of the most important treatments in clinical practice to improve tissue oxygenation. In the CRIT study, $44 \%$ of patients admitted to ICU received at least one RBC treatment and the mean time to first transfusion was $2.3 \pm$ 3.7 days [3]. However, over the last two decades concerns have been raised that the possible risk of blood transfusion may outweigh the benefits. Studies in trauma, sepsis and acute respiratory distress syndrome (ARDS) patients reported a nonimprovement in tissue oxygen delivery [11-13], or even a decreased oxygenation through the storage and preparation of RBCs $[14,15]$. The use of allogeneic blood is also associated with potential adverse effects, including immunosuppression [16], risk for infection, transfusion reactions [17] and transfusion-related acute lung injury (ALI) (TRALI) [18]. Most seriously, blood transfusion may be associated with higher mortality [2,3,19]. A meta-analysis published in 2008 demonstrated an association between RBC transfusion and mortality in critically ill patients: 12 published studies were included, and the pooled odds ratio (OR) was 1.7 (95\% confidence interval (CI), 1.4 to 1.9) [20]. However, this association has recently been questioned. Some studies reported that RBC transfusion was associated with a lower rate of mortality. Sakr et al. reported a decreased risk of in-hospital death in blood-transfused surgical ICU patients (relative risk (RR) $0.96,95 \%$ CI 0.95 to 0.98 ), especially in patients aged from 66 to 80 years, in patients admitted to the ICU after noncardiovascular surgery, in patients with severe sepsis and in patients with high simplified acute physiology score II (SAPS II) or sepsis-related organ failure assessment (SOFA) scores [21]. More recently, Park et al. found a lower risk of in-hospital death in transfused patients with severe sepsis and septic shock (HR 0.51, 95\%CI, 0.39 to 0.69) [4]. Despite all the controversy, clinical practice had been improved by the growing recognition of transfusion-related risks. Bilgin et al. and Hebert et al. had reported decreased mortality among patients receiving prestorage leukoreduced blood compared to patients receiving nonfiltered blood [22,23], indicating that leukocytes from donated blood may be crucial in the development of immune system suppression. Another transfusion practice is using 'fresh' transfused RBCs instead of 'old' blood; some studies suggested that the use of old stored RBCs is a potential risk factor for mortality $[24,25]$. There is also a transfusion practice for ICU patients considering a low transfusion threshold safer. A multicenter, randomized controlled trial (RCT) by Hebert et al., comparing liberal (Hb level, 10 to $12 \mathrm{~g} / \mathrm{dL}$ ) and restrictive (Hb level, less than $7 \mathrm{~g} / \mathrm{dL}$ ) RBC transfusion strategy, showed that the restrictive strategy could decrease rates of organ dysfunction, cardiac complications and mortality [26].

As research on the benefits and risks of RBC transfusion gains popularity, however, the results from previous studies remain confusing: is allogeneic RBC transfusion beneficial or harmful to ICU patients? And what kind of transfusion practices are effective in decreasing mortality? We thus conducted a meta-analysis of published retrospective and prospective observational studies comparing $\mathrm{RBC}$ transfused with nontransfused ICU patients to assess: (1) all-cause in-hospital mortality rate and (2) risk factors of death in transfused patient.

\section{Methods}

\section{Data sources and searches}

We followed the Strengthening the Reporting of Observational Studies in Epidemiology (STROBE) statement for observational studies [27]. We used a comprehensive search strategy to identify all potentially relevant studies by searching Medline, Web of Science and EMBASE. Databases were searched regardless of language and geography, and the published time restricted to 1980 through 31 May 2013. The search used terms ('mortality') AND ('blood transfusion' OR 'anemia' OR 'erythrocyte transfusion'). To identify additional studies, reference lists of retrieved articles were also evaluated.

\section{Study selection}

Two reviewers (YZ and CL) independently reviewed and extracted studies abided by the following inclusion criteria: (1) studies on adult subjects, or patients aged older than 16 years, (2) studies enrolling subjects from ICUs (medical or surgical), (3) studies dividing subjects into two groups according to whether they received transfusion or not, and reporting results focused on allcause in-hospital mortality rate. For hospitalized ICU patients, in-hospital mortality is a short-term mortality, as Vincent et al. investigated that transfused patients admitted to ICU had a mean hospital length of stay (LOS) of 15.8 (9.0) days [2], and Sakr et al. found that the hospital LOS of surgical ICU patient was from 9 to 19 days, with a mean value of 12 days [21]. So our review was focused on in-hospital mortality of less than a month. Exclusion criteria were as follows: (1) studies on senior subjects, defined as aged more than 80 years, and (2) case reports or reviews. 
All titles and abstracts reporting on blood transfusion and mortality were reviewed. All abstracts reporting on the association between blood transfusion and mortality or mobility were selected for full-text review.

\section{Data extraction}

The primary outcome of interest was in-hospital mortality of transfused ICU patients comparing transfused (exposed group) versus nontransfused ICU patients. While extracting data, we found that except for 'in-hospital mortality' rate, some studies reported a '28-day mortality' rate or '30-day mortality' rate, in our review both were regarded as approximate 'in-hospital mortality' rate. In some of the studies, both adjusted results (OR, or RR, or hazard ratio (HR)) and count data (the numbers of survivors and nonsurvivors) were provided; or both propensity matched results and no propensity matched results were available. In these situations, we selected data for our meta-analysis complying with the following rules: (1) adjusted results had precedence over count data; (2) HR and RR estimates had precedence over OR estimates; (3) propensity matched results had precedence over no propensity matched results. The secondary outcomes were factors associated with transfusion status. We extracted relevant data from the literature as follows: (1) the type of reported effect size, (2) publication year, (3) adjustment for confounder, (4) mean admission $\mathrm{Hb}$ level, (5) percentage of patients transfused in ICU, (6) mean volume of transfused RBCs per patient, (7) mean pretransfusion $\mathrm{Hb}$ level, (8) mean admission APACHE II score, (9) leukodepleted blood measurement, (10) mean age of patients, and (11) type of patient.

\section{Study quality assessment}

The Strengthening the Reporting of Observational Studies in Epidemiology (STROBE) statement for observational studies [27] was used to assess the quality of the included studies. The STROBE statement provided a checklist of six domains including title and abstract, introduction, methods, results, discussion and other information sections of articles to assess the quality of the observational studies. Each of these domains was evaluated as low or high risk of bias. Overall quality of the article was assessed as low (high risk of bias in more than five domains), median (high risk of bias in three or four domains), high (high risk of bias in one or two domains) and very high (high risk of bias in none of the domains). Only primary outcome (all-cause in-hospital mortality) was used to assess the risk of bias.

\section{Data synthesis and analysis}

We used comprehensive meta-analysis software version 2.0 (Biostat, Englewood, NJ, USA) [28] to estimate pooled effect size. RR was chosen as the common measurement of association across studies, and a random effects model was used to generate a pooled RR estimate. HR was considered as RR directly. OR was transformed into $R R$ if feasible. If effect estimates of mortality were not available from the original article, then the effect size was derived from the standard $2 \times 2$ table. The method used for transformation from OR to RR was according to Zhang et al. [29]:

$$
R R=O R /\left[\left(1-P_{0}\right)+\left(P_{0} \times O R\right)\right]
$$

And the standard error of $\log R R$ is:

$$
S E(\log R R)=S E(\log O R) \times \log R R / \log O R
$$

$P_{0}$ represent the mortality rate in the nonexposed group.

When $P_{0}$ was not available, then OR was directly considered as RR. Because the transformation can underestimate the variance of the RR derived from the OR [30], a sensitivity analysis was performed excluding studies that did not report adjusted RR or HR as the effect size. Another sensitivity analysis was performed excluding studies with low or median study quality. Meta-regression analyses using unrestricted maximum likelihood model were performed to assess the factors explaining the heterogeneity of risk ratios across studies. Stratified analyses were performed to assess the impact of transfusion status and mortality. Forest plots were constructed for selected studies, and $Q$ statistic and $I^{2}$ index were calculated to assess heterogeneity of outcome measures across studies. Begg's rank correlation test and funnel plots were performed to detect publication bias through visual inspection. We assessed small study effect through the trim-and-fill method.

\section{Ethical approval}

This study was reviewed and approved by the research ethics committee of School of Public Health, Tongji Medical College, Huazhong University of Science and Technology, Wuhan, China on 25 February 2013. Consent from patients was irrelevant in the present study (a systematic review).

\section{Results}

\section{Study selection}

The initial literature search yielded 978 studies (Figure 1). The titles and abstracts were examined independently by two authors to identify potentially relevant studies. After preliminary screening, 115 studies were left for full-text review. By searching potentially relevant articles from references, we further identified 11 studies for full-text review, but none of them met the inclusion criteria. Finally, 18 studies (28,797 participants) were identified as relevant to the investigation of mortality of transfused 


\section{Citations identified from electronic searches $(n=978)$}

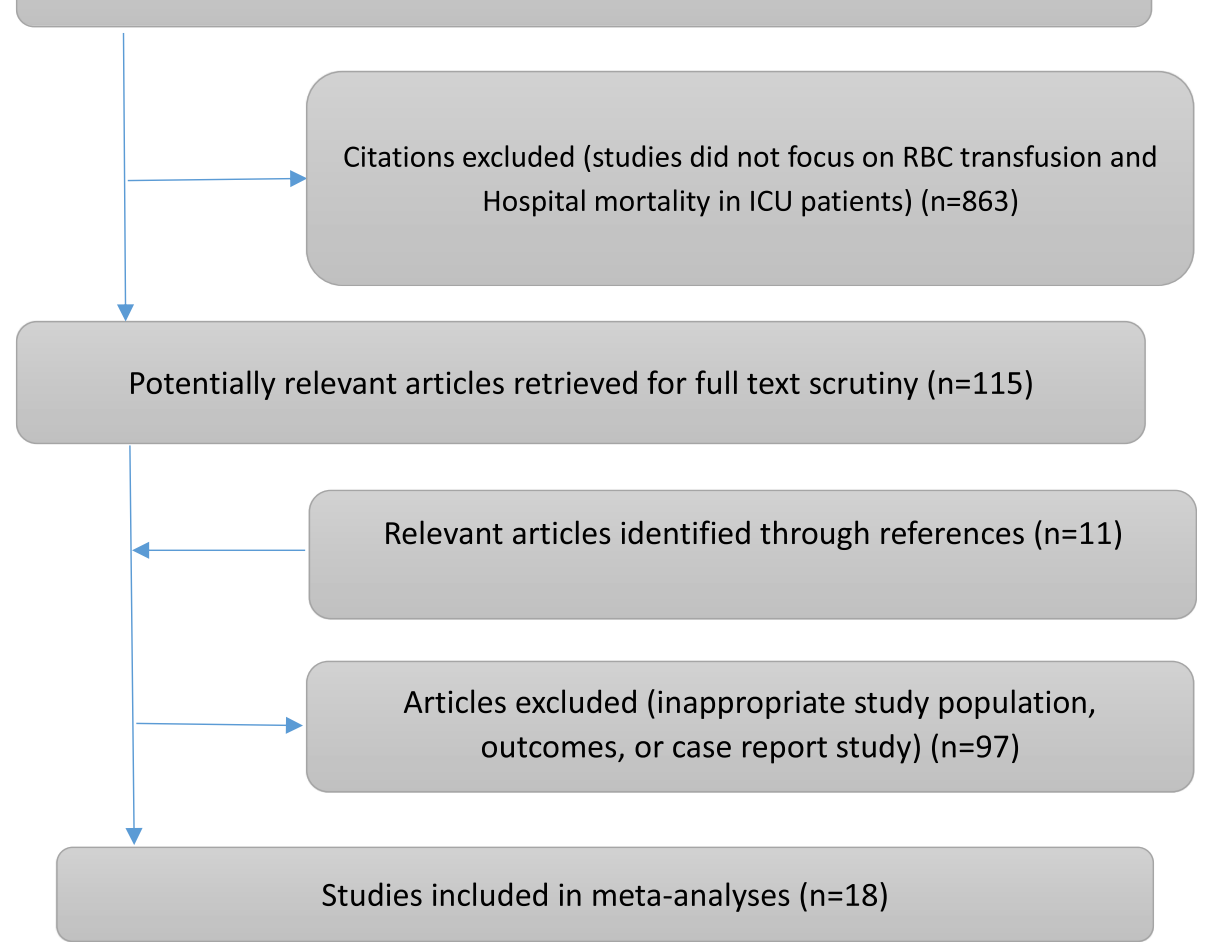

Figure 1 Details of study selection for systematic review.

ICU patients, all of which were observational studies. Eight studies were prospective and the other ten retrospective. For one study [31], the authors reported an obvious wrong effect size, with the OR 2.46, and its 95\% CI 3.17 to 11.56 . We calculated the crude effect value through count data, and the crude OR $(95 \% \mathrm{CI})$ was 5.33 (3.17 to 11.56). Table 1 provides detail information of the 18 included studies [2-4,19,21,31-43].

\section{Risk of bias assessment}

The risk of bias assessment is represented in Figure S1 in Additional file 1 . We found that, title/abstract, introduction, results and discussion sections had a low risk of bias, other information had a median risk of bias and methods had a high risk of bias. Only one study did not indicate the study's design clearly [31]. Two studies did not discuss limitations of the study and take any sources of potential bias or imprecision into account [31,32]. Analyses of subgroups were not reported in three studies [32,42,43]; eleven studies did not provide information on handling of missing data. Six studies reached very high overall quality $[2,34,35,37,39,41]$, nine studies reached high overall quality $[4,19,21,33,36,38,40]$, and the other three studies reached median overall quality $[31,32,42]$, no study reached low overall quality. All risk of bias assessments were conducted by two authors (YZ and CL). Disagreements were resolved by consensus.

\section{Synthesis of results}

The overall pooled risk ratio of in-hospital mortality of transfused patients compared to nontransfused was about 1.431 (95\%CI, 1.105 to 1.854 ) (Figure 2).

Sensitivity analyses were presented in Table 2. When excluding studies that did not adjust for any confounding factors, the estimated association of RBC transfusion with in-hospital mortality was null (RR 1.211, 95\%CI, 0.975 to 1.505) (Figure 3). When we excluded studies with median or low quality, there was also no association (RR 1.178, 95\%CI, 0.937 to 1.481 ) (Figure 4). When we excluded studies without reporting $\mathrm{HR}$ or $\mathrm{RR}$ as the effect size measurement, still there was no significant association (RR $0.901,95 \%$ CI 0.622 to 1.305) (Figure 5). Subgroup analyses were stratified by type of study patients, type of reported effect size, confounder adjustment methods and leukodepleted blood measurement (Table 3) (Figure S2 in Additional file 2, Figure S3 in Additional file 3, Figure S4 in Additional file 4 and Figure S5 in Additional file 5). Results of subgroup analyses suggested that blood transfusion was a risk factor in studies enrolling patients from all ICU admissions (RR 1.513, 95\%CI 1.123 to 2.039), 
Table 1 Details of studies included in meta-analysis $(n=18)$

\begin{tabular}{cc}
\hline Study & Study designation \\
\hline Vincent et al. [2] & $\begin{array}{r}\text { Prospective, multiple center, observational } \\
\text { study in western Europe }\end{array}$ \\
Corwin et al. [3] & $\begin{array}{c}\text { Prospective, multiple center, observational } \\
\text { cohort study in the United States }\end{array}$ \\
Robinson et al. [32] & Retrospective, observational study \\
Croce et al. [31] & Retrospective, observational study \\
Taylor et al. [19] & Prospective, observational, cohort study \\
Netzer et al. [33] & Prospective, cohort study
\end{tabular}

Ruttinger et al. [34] Retrospective, observational cohort study

Vincent et al. [35]

Bochicchio et al. [36]

Bursi et al. [37]

Engoren et al. [38]

Sakr et al. [21]

Parsons et al. [39]

$$
\text { study }
$$

\section{Prospective}

Retrospective observational study

Retrospective study

Retrospective study

A secondary analysis

\section{Inclusion population}

All ICU patients

Not reported

Not reported

Patients with blunt injury and ISS $<25$, survival of at least 48 hours, and no blood transfusion within the first 48 hours from admission

All ICU admissions

Patients with ALI/ARDS

All consecutive cases admitted immediately or delayed after a

surgical procedure

All ICU patients

$$
\text { to the ICU }
$$

Stable patients after elective major vascular surgery

\section{All ICU patients}

All surgical ICU patients

Patients with new-onset ALI,

\section{Exclusion population}

Not reported

Admission to a pediatric, cardiothoracic, cardiac, neurologic, or burn ICU; renal failure on dialysis

Patients with blunt hepatic, splenic or both injuries

Patients who received any transfusion within the first 48 hours from admission, ISS > = 25

\section{Not reported}

Patients were excluded if they had current or prior congestive heart failure, respiratory disease, or conditions that mimicked ALI/ARDS,

including vasculitis with diffuse alveolar

hemorrhage; were burned $30 \%$ of total body area; or were lung or bone marrow recipients.

Patients who had not undergone surgery during their present hospital stay and who had been admitted only for medical reasons, and patients with a rapidly fatal clinical course or with minimal disease severity

Not reported

Not reported sepsis and shock

Patients who had hemorrhagic hypovolemic shock requiring emergency RBC transfusion, severely anemic

Cardiac surgical patients

Not reported

Patients with trauma or multiple transfusion

\section{Adjustment for confounding}

Patients' admission variables

Propensity to receive a transfusion

Shock indices and associated injury severity

We use original numbers to analyze RR, because the author reported 3.17 to 11.56 ) Unadjusted

Age, gender, APACHE III score, and precipitating event

Admission variables, maximum APACHE II score, maximum number of failing organs, duration of invasive ventilation, duration of catecholamine therapy, and duration of renal replacement therapy

Sex and age, type of admission, main medical history, fluid balance, SAPS $\|_{,}$ and severity of organ dysfunction on admission as SOFA score

Age, sex, race, and ISS

Baseline characteristics, surgical risk, bleeding, presence of anemia, and propensity to receive transfusion

APACHE II scores and propensity to receive a transfusion

Patients' propensity to receive a

$$
\text { transfusion }
$$

Age, sex, race, randomization arm and APACHE III score 
Table 1 Details of studies included in meta-analysis $(\mathbf{n}=\mathbf{1 8})$ (Continued)

\begin{tabular}{|c|c|c|c|c|}
\hline Sheth et al. [40] & Retrospective, observational cohort study & $\begin{array}{l}\text { Patients with intracerebral } \\
\text { hemorrhage }\end{array}$ & $\begin{array}{l}\text { Patients younger than } 18 \text { years of age or with } \\
\text { ICH secondary to antecedent head trauma, } \\
\text { acute ischemic stroke with hemorrhagic } \\
\text { transformation, brain tumor, vascular } \\
\text { malformation, venous thrombosis, vasculitis } \\
\text { of the central nervous system, hematological } \\
\text { malignances, blood dyscrasia, or coagulopathy }\end{array}$ & $\begin{array}{l}\text { Anemia, warfarin use, admission GCS } \\
\text { score, hematoma volume, hematoma } \\
\text { location, and DNR/CMO status }\end{array}$ \\
\hline Park et al. [4] & Prospective, multicenter observational study & $\begin{array}{l}\text { Patients with severe sepsis or } \\
\text { septic shock }\end{array}$ & Not reported & Propensity to receive a transfusion \\
\hline Brophy et al. [41] & A cross-sectional retrospective study & Anemia and renal dysfunction & $\begin{array}{c}\text { Patients with anemia of neoplastic diseases or } \\
\text { those receiving chemotherapy }\end{array}$ & $\begin{array}{l}\text { Age, race, sex, ICU LOS, ESA use, } \\
\text { transfusion status, mechanical ventilation } \\
\text { or CPAP status, vasopressor use, severity } \\
\text { of, illness, and presence of, following } \\
\text { comorbid conditions, Gl bleed, } \\
\text { sepsis, and neurologic injury. }\end{array}$ \\
\hline Silva et al. [42] & Prospective observational cohort study & All ICU admissions & $\begin{array}{c}\text { Acute coronary syndrome, ischemic stroke, } \\
\text { acute hemorrhage, prior transfusion, pregnant } \\
\text { women and Jehovah's Witnesses }\end{array}$ & $\begin{array}{l}\text { Sex, origin, previous disease, } \\
\text { ventilation mode }\end{array}$ \\
\hline Sekhon et al. [43] & Retrospective cohort study & Severe TBI patients & $\begin{array}{l}\text { Nontraumatic etiology, consciousness, } \\
\text { concomitant traumatic quadriparesis }\end{array}$ & $\begin{array}{l}\text { Age, admission GCS score, insertion } \\
\text { of EVD, mean 7-day hemoglobin }\end{array}$ \\
\hline
\end{tabular}

APACHE, acute physiology and chronic health evaluation; CPAP, continuous positive airway pressure; DNR/CMO, do not resuscitate/comfort measures only; ESA, erythropoiesis-stimulating agents; EVD, external ventricular drain; GCS, Glasgow coma score; GI, gastrointestinal; ICU, intensive care unit; LOS, length of stay; OR, odds ratio; RBC, red blood cells; RR, relative risk; SAPS, simplified acute physiology score; SOFA, sepsis-related organ failure assessment; TBI, traumatic brain injury. 
studies that reported OR as the effect size (RR 1.465, 95\%CI, 1.049 to 2.045), studies that did not adjust for any confounders ( $R R$ 3.933, 95\% CI 2.107 to 7.343) and studies that did not provide available information on leukoreduction (RR 1.851, 95\%CI, 1.229 to 2.786), while other subsets of studies suggested that RBC transfusion was not associated with mortality.

To assess factors responsible for heterogeneity of effect sizes across studies, we conducted meta-regression analyses. Six potential factors (publication year, mean admission $\mathrm{Hb}$ level, mean units transfused per patients, mean pretransfusion $\mathrm{Hb}$ level, mean admission acute physiology and chronic health evaluation II (APACHE II) score, and mean age of patients) were considered. The results suggested that publication year (coefficient $-0.1056, P=0.048$ ) and mean age of patient (coefficient $-0.0417, P=0.002$ ) had a significant influence. Table 4 summarizes the metaregression analyses. In our meta-analysis, only two of the eighteen included studies had information on storage duration of RBCs $[19,34]$, we thus could not conduct analysis on this topic.

\section{Publication bias}

There was significant heterogeneity $(P=0.007)$ across studies. Visual inspection of the funnel plot (Figure S6 in Additional file 6) indicated the presence of a moderate publication bias. Begg's test suggests that significant publication bias was not likely $(P=0.570)$. Furthermore, when looked for missing studies using the trim-and-fill random effects model, no studies needed to be imputed.

\section{Discussion}

Whether RBC transfusion is linked to higher or lower mortality in critically ill patients has been a matter of debate for more than a decade. Our review was aimed to determine whether allogeneic RBC transfusion is beneficial or harmful for ICU patients, and clarify the nature

Table 2 Details of sensitivity analysis of pooled risk ratio $(95 \% \mathrm{Cl})$ for in-hospital mortality

\begin{tabular}{|c|c|c|c|c|c|}
\hline & $\begin{array}{c}\text { Number of studies } \\
\text { excluded }\end{array}$ & $\begin{array}{l}\text { Number of studies } \\
\text { included }\end{array}$ & $\begin{array}{l}\text { Effect size } \\
(95 \% \mathrm{Cl})\end{array}$ & $\begin{array}{l}\text { Homogeneity } \\
\text { index, } Q\end{array}$ & $\begin{array}{l}\text { Between-study } \\
\text { variability, }\left.\right|^{2}\end{array}$ \\
\hline $\begin{array}{l}\text { Excluded studies did not give } \\
\text { confounder-adjusted estimates }\end{array}$ & $2[19,31]$ & 16 & 1.211 (0.975 to 1.505$)$ & $114.881, P<0.01$ & 86.943 \\
\hline $\begin{array}{l}\text { Excluded studies got a 'moderate' } \\
\text { or 'low' risk of bias }\end{array}$ & $3[31,32,42]$ & 15 & $1.178(0.937$ to 1.481$)$ & $144.866, P<0.01$ & 90.336 \\
\hline $\begin{array}{l}\text { Excluded studies did not reported } \\
\text { RR or HR as effect size measurement }\end{array}$ & $12[3,19,31-34,36,39-43]$ & 6 & 0.901 (0.622 to 1.305$)$ & $31.039, P<0.01$ & 91.391 \\
\hline
\end{tabular}

$\mathrm{Cl}$, confidence interval; $\mathrm{HR}$, hazard ratio; $\mathrm{RR}$, relative risk. 


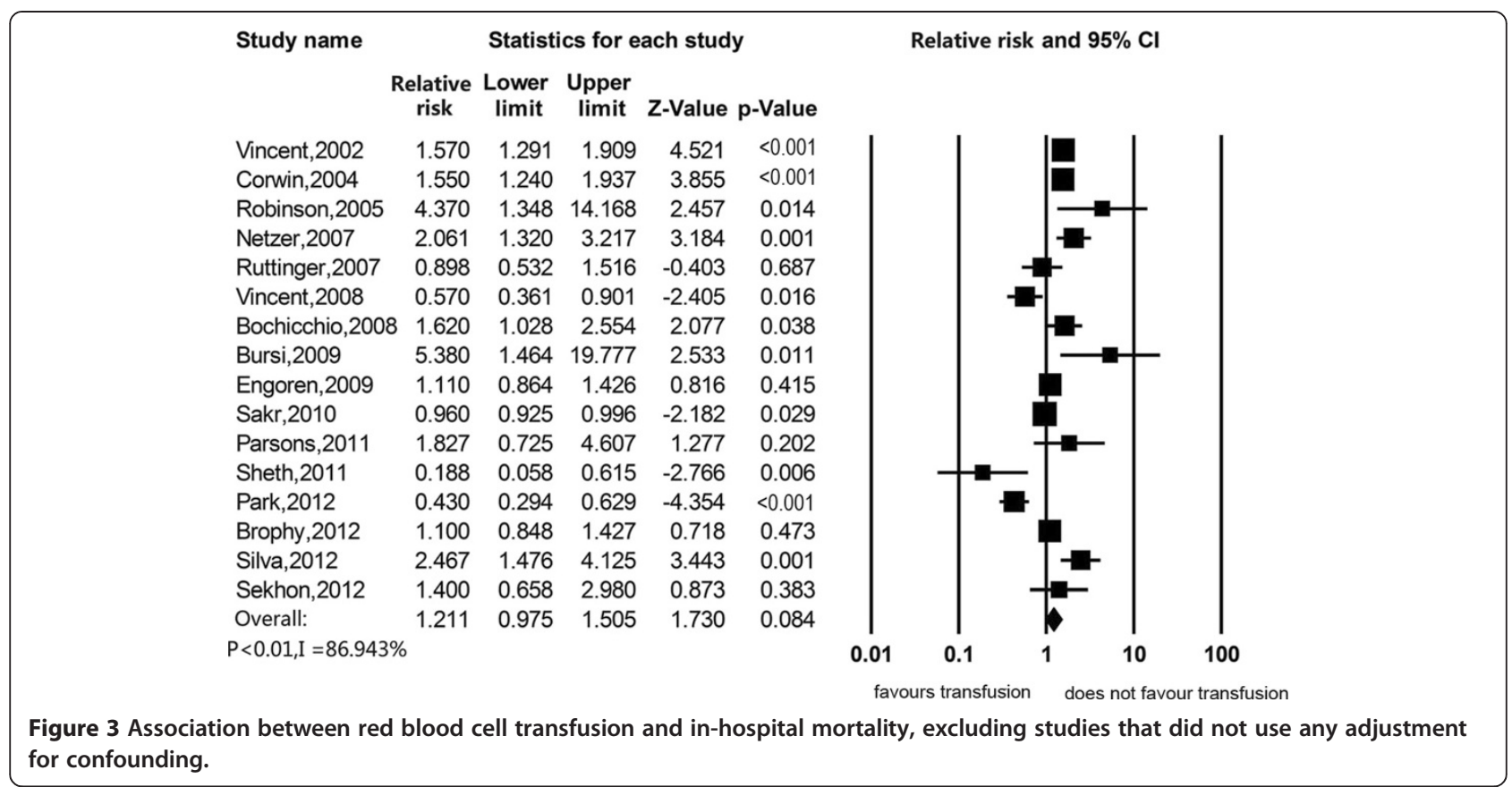

of discrepancies among previous observation studies. The main findings are as follows.

a. There is no consistent evidence linking $\mathrm{RBC}$ transfusion to in-hospital mortality in ICU patients The initially overall pooled results suggested that allogeneic blood transfusion was associated with an $11 \%$ to $85 \%$ increased risk for in-hospital mortality. However, after excluding studies with unadjusted estimates only $[19,31]$ or studies with median overall quality $[31,32,42]$, the association became null.
Therefore, we could not draw a definitive conclusion. The results of sensitivity analyses suggested that such risk association may be attributable to studies without adjustment for confounders. In studies adjusted for confounders, studies that reached effect size by using the Cox regression model, and studies that implemented detailed information about leukodepleted blood measurement, we found that RBC transfusion did not increase risk of in-hospital death.

b. There is no evidence indicating that RBC transfusion is associated with increased mortality in

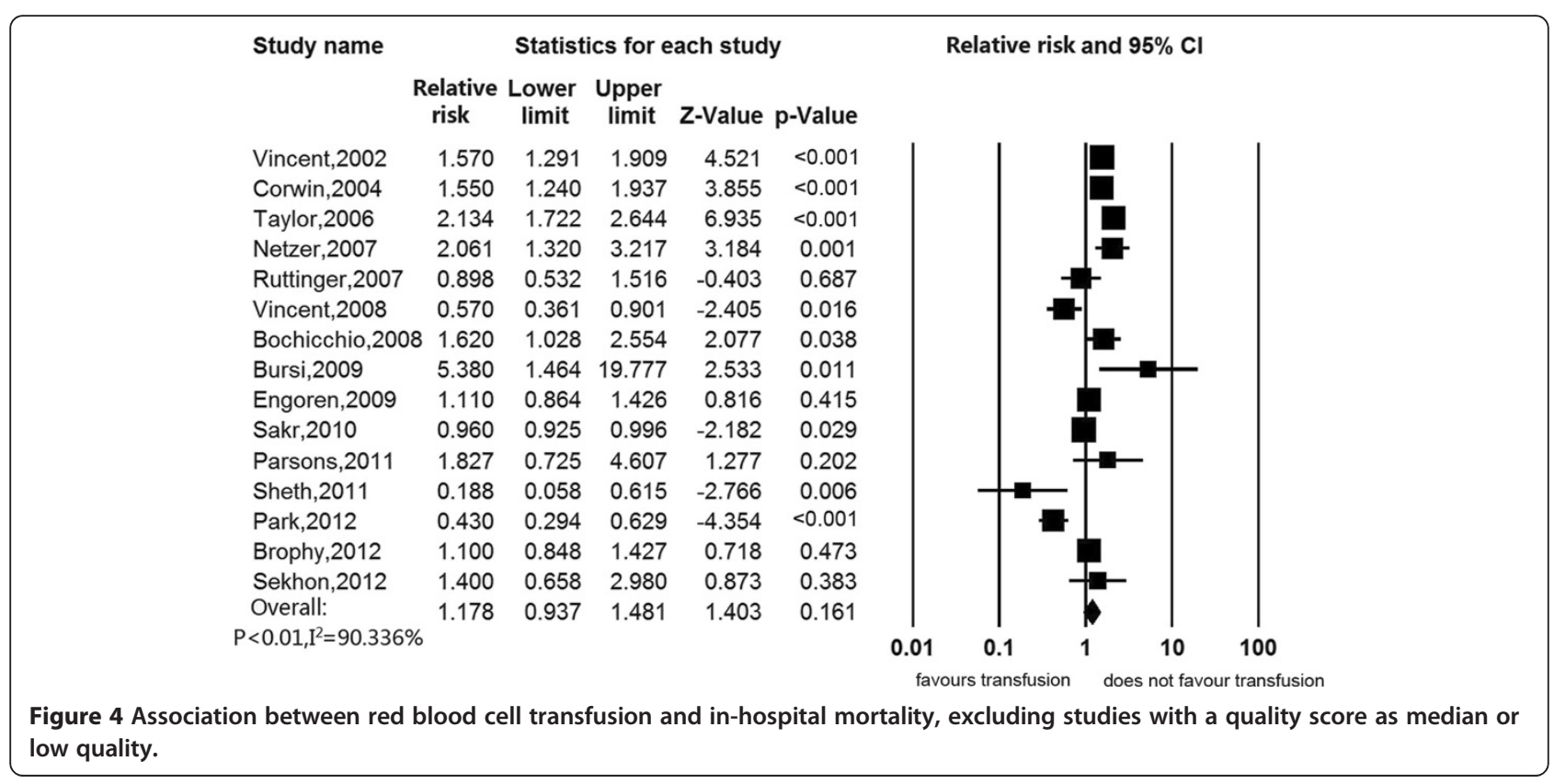




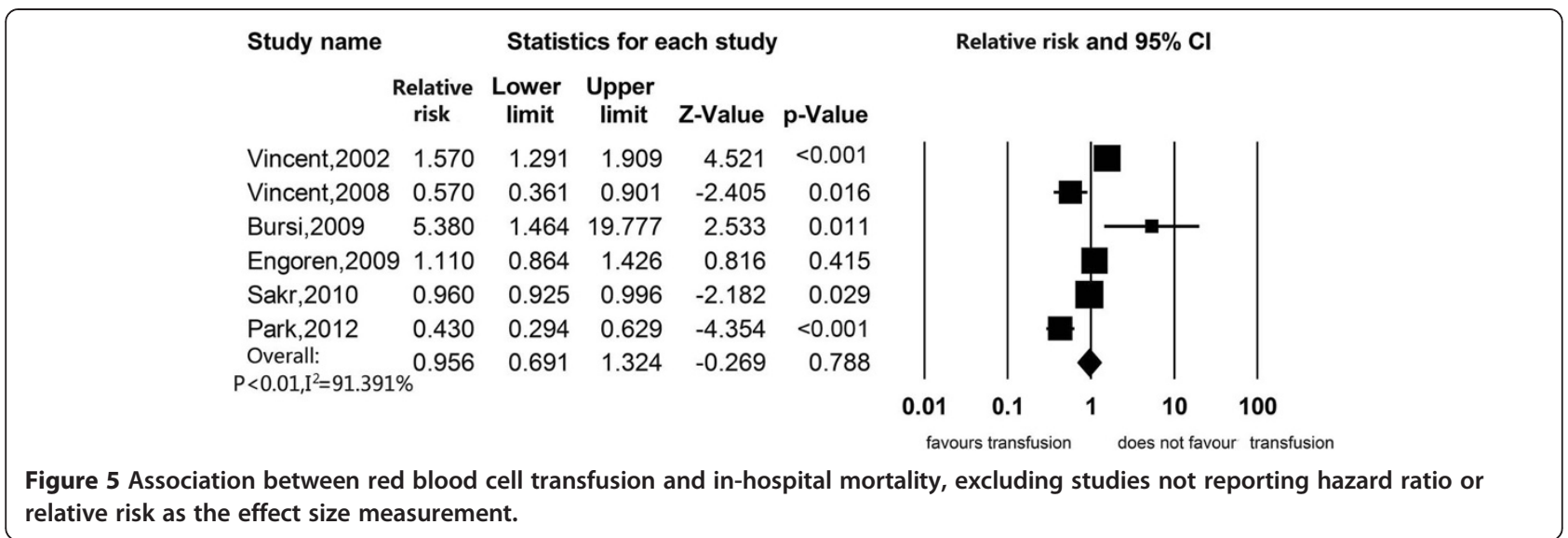

patients admitted to ICU for sepsis and shock, trauma and surgical reasons.

Type of patients is an extremely important confounder for survival after RBC transfusion. Different types of patients have different responses to RBCs transfusion. For example, age of transfused $\mathrm{RBCs}$ could potentiate the risk association of volume of $\mathrm{RBC}$ transfused in trauma patients, but less so in other types of patients $[44,45]$. In our subgroup analysis, we separate enrolled studies into four groups according to patients' population: all ICU admissions (seven studies), sepsis and shock (two studies), surgical (three studies), trauma (three studies), and others (three studies, one on patients with ALI or ARDS, one on patients with intracerebral hemorrhage, and one on patients with anemia and renal dysfunction). As presented in Table 3, the results suggested that there was no association between RBC transfusion and mortality in sepsis and shock, surgical, trauma and 'other' patients. The pooled overall effect estimate of seven studies on all ICU admissions was significant (RR 1.513, 95\%CI 1.123 to 2.039). However, in these seven studies, we noticed that one study did not

Table 3 Details of subgroup analysis of pooled risk ratio $(95 \% \mathrm{Cl})$ for in-hospital mortality

\begin{tabular}{|c|c|c|c|c|}
\hline & Number of studies included & Effect size $(95 \% \mathrm{Cl})$ & Homogeneity index, $\mathrm{Q}$ & Between-study variability, $I^{2}$ \\
\hline \multicolumn{5}{|l|}{ Type of patient } \\
\hline All ICU & $7[2,3,19,32,35,38,42]$ & 1.513 (1.123 to 2.039$)$ & $39.822, P<0.01$ & 84.933 \\
\hline Sepsis and shock & $2[4,39]$ & 0.831 (0.203 to 3.413$)$ & $8.041, P=0.005$ & 87.563 \\
\hline Surgical & $3[21,34,37]$ & $1.174(0.682$ to 2.023$)$ & $6.793, P=0.033$ & 70.556 \\
\hline Trauma & $3[31,36,43]$ & 2.705 (0.815 to 8.973$)$ & $30.695, P<0.01$ & 93.484 \\
\hline Other & $3[33,40,41]$ & 0.940 (0.417 to 2.116$)$ & $15.505, P<0.01$ & 87.101 \\
\hline \multicolumn{5}{|l|}{ Outcome measurement } \\
\hline Count data & $2[19,31]$ & 3.969 (2.023 to 7.788$)$ & $28.936, P<0.01$ & 96.544 \\
\hline OR & $10[2,3,32-34,36,39-42]$ & 1.465 (1.049 to 2.045$)$ & $30.191, P<0.01$ & 70.190 \\
\hline $\mathrm{RR}$ and $\mathrm{HR}$ & $6[4,21,35,37,38,43]$ & 0.901 (0.622 to 1.305$)$ & $31.039, P<0.01$ & 91.391 \\
\hline \multicolumn{5}{|l|}{ Adjustment } \\
\hline Unadjusted & $2[19,31]$ & 3.933 (2.107 to 7.343$)$ & $28.936, P<0.01$ & 96.544 \\
\hline $\begin{array}{l}\text { No propensity matched } \\
\text { but multiple adjusted }\end{array}$ & $9[2,32-34,39-41,43]$ & $1.358(0.965$ to 1.910$)$ & $25.626, P<0.01$ & 68.782 \\
\hline Propensity score matched & $7[3,4,21,35,37,38,42]$ & 1.089 (0.767 to 1.546$)$ & $60.523, P<0.01$ & 90.086 \\
\hline \multicolumn{5}{|l|}{ Leukoreduced usage } \\
\hline Not reported & $11[31-34,36,37,39-43]$ & 1.851 (1.229 to 2.786$)$ & $86.863, P<0.01$ & 88.488 \\
\hline$<50 \%$ & $3[2,4,19]$ & 1.155 (0.583 to 2.290$)$ & $52.156, P<0.01$ & 96.165 \\
\hline$\sim 76 \%$ & $2[3,35]$ & $0.966(0.412$ to 2.267$)$ & $14.812, P<0.01$ & 93.249 \\
\hline$\sim 100 \%$ & $2[21,38]$ & 1.031 (0.452 to 2.352$)$ & $1.261, P=0.26$ & 20.696 \\
\hline
\end{tabular}

$\mathrm{Cl}$, confidence interval; $\mathrm{HR}$, hazard ratio; ICU, intensive care unit; $\mathrm{RR}$, relative risk. 
Table 4 Details of meta-regression of slope coefficients for in-hospital mortality

\begin{tabular}{ccccc}
\hline & Number of studies & Coefficient $(\mathbf{9 5 \%} \mathrm{Cl})$ & $\boldsymbol{P}$ value \\
\hline Age of patient & $18[2-4,19,21,31-43]$ & $-0.0417(-0.0680$ to -0.0154$)$ & 0.002 \\
Publication year & $18[2-4,19,21,31-43]$ & $-0.1056(-0.2103$ to -0.0009$)$ & 0.048 \\
Admission Hb & $9[2-4,21,38-42]$ & $-0.1848(-0.4343$ to 0.0648$)$ & 0.147 \\
Units transfused & $12[2,3,19,21,31,32,35-37,42,43]$ & $-0.1676(-0.3856$ to 0.0504$)$ & 0.132 \\
Pretransfusion Hb & $7[2-4,21,34,42,43]$ & $-0.2157(-0.8588$ to 0.4275$)$ & 0.511 \\
APACHE II & $8[2-4,21,34,38,40,42]$ & $0.0202(-0.0569$ to 0.0973$)$ & 0.607 \\
\hline
\end{tabular}

APACHE II, acute physiology and chronic health evaluation $\mathrm{Il}$; $\mathrm{Cl}$, confidence interval; $\mathrm{Hb}$, hemoglobulin.

adjust for any confounders, therefore had a high risk of bias [19]. Actually, after excluding this study, we observed a 7\% reduction but still significant pooled overall effect estimate (RR 1.406, 95\% 1.016 to 1.945). In a large, multiple center study by Vincent et al., admission type of patients were elective surgery (41.4\%), medical (32.6\%), emergency surgery (16.6\%), trauma (7.6\%) and other (1.6\%) [2]. In our analysis, we were unable to identify medical ICU patients as an independent subgroup. Literature on the safety of RBC transfusion in medical ICU patients was poor. In the SOAP study, medical admission was found to be an independent predictor for risk of 30-day mortality in ICU patients (RR 1.47, 95\% 1.24 to 1.74) [35]. Further studies are needed to identify whether medical admissions are less tolerant of RBC transfusion than other patient populations.

c. There is a lack of evidence on whether leukodepleted RBC transfusion could reduce in-hospital mortality in ICU patients.

Immunomodulating effects of transfused RBCs have been suggested as potential cause of many adverse effects [46]. Leukocytes from donated blood may play a key role in immune system suppression; however, the exact mechanism is unclear [47]. Studies had reported a decrease in mortality rate among patients receiving prestorage leukoreduced blood compared to patients receiving nonfiltered blood [22,23]; however, a meta-analysis of 12 RCTs comparing leukodepleted and nonleukodepleted RBCs failed to identify an association between leukoreduction and mortality (OR 1.14, 95\%CI, 0.89 to 1.45) [48]. Of the eighteen studies included in our review, only seven of them had information on percentage of patients receiving nonfiltered blood. Filtered RBCs were routinely used in two studies, Sakr et al. [21] suggested that RBC transfusion was independently associated with lower risk of mortality (RR 0.96, 95\%CI, 0.95 to 0.98) while Engoren et al. [38] found no association. In our subgroup analyses, studies were divided into four groups according to the usage of leukoreduction. In a subset of 11 studies that did not report information on leukoreduction, the pooled effect estimate suggested that RBC transfusion was associated with higher mortality (RR 1.851, 95\%CI, 1.229 to 2.786); however, the pooled effect estimates of other subgroups were not significant, regardless of the degree of implementation of leukodepleted blood (Table 3). Studies lacking information on leukoreduction had a higher risk of in-hospital mortality. Because of insufficient information, we cannot tell whether the use of leukodepleted blood could decrease mortality in transfused patients. Another possible explanation is that studies lacking leukoreduction information also had lower qualities, hence indicating high risk of bias. We recommend that further studies should take leukoreduction implementation into consideration.

d. Study and statistical analysis methods are of considerable importance in explaining the association between RBC transfusion and in-hospital mortality.

To model the association between RBC transfusion and in-hospital mortality, 10 of the 18 included studies used multivariable logistic regression, and reported OR as the outcome measurement. Pooled effect estimate of this subset of studies found that there is a risk association between $\mathrm{RBC}$ transfusion and mortality (RR $1.465,95 \% \mathrm{CI}, 1.049$ to 2.045 ). In contrast, in five studies used Cox regression, there was no independent association between RBC transfusion and mortality (RR 0.901, 95\%CI, 0.622 to 1.305$)$. This may be because that selection of statistical model may have effect on the final result. As logistic regression did not take time-dependent variables into consideration, with increasing follow-up time, the logistic regression coefficients become less reliable [49]. For the same transfusion data, treating transfusion and living status as a time-dependent variable or not may result in different conclusions. Our review suggests that the statistical analysis method may cause disagreement between previous studies. 
Previous research revealed that older and more severely ill patients were more likely to have comorbidities after RBC transfusion [2,4]. The quality of a study relies on the completeness of data on possible confounders [34]. Patients' admission characteristics and disease severity are two major confounders that can have an impact on transfused patients' risk of death. Multivariable confounderadjustment analyses and propensity score analyses are implemented in most of the studies to control imbalances between transfused and nontransfused groups. Under propensity matched groups, patients were matched by their probability to receive a transfusion, thus statistically reducing confounding bias. Previous findings revealed that propensity score analysis could produce estimates that were more precise and robust than regular logistic regression while there were seven or fewer events per confounding variables, but might produce unstable estimates when events per confounder were more than eight [50]. Most of our included studies reported multivariable confounder-adjusted estimates (Table 3), and the mostly used confounders in adjustments were patient characteristics at admission including age, gender and admission symptom score; seven studies used propensity score analyses. Subgroup analyses of the seven propensity score matched studies and the other nine no propensity score matched confounder-adjusted studies all showed no association between RBC transfusion and death (RR 1.089, 95\%CI, 0.767 to 1.546; RR 1.358, 95\% CI, 0.965 to 1.910 respectively), while the other two studies with unadjusted effect estimates only showed an increased risk (RR 3.933, 95\%CI 2.107 to 7.343). This suggests that studies that did not fully adjust for confounders may overestimate the negative effects of RBC transfusion. This finding supported the view of Ruttinger et al. [34] that RBC transfusion may be only a surrogate marker for disease severity and is not causally related to mortality. Ruttinger's study even suggested the pitfalls of propensity score and multivariate analyses; both cannot adjust for unobserved or unknown confounders, and not all factors that may influence transfusion practice had been collected. Ruttinger considered variables reflecting disease severity during ICU stay, and found that the number of RBC transfusion units was associated with increased mortality, and the association attenuated but persisted while only adjusted for admission variables. When controlling for variables of disease severity during ICU stay, this association vanished. Disease severity during ICU stay might be particularly important. We suggest that further research should take this into consideration.
In our review, we performed meta-regression analyses to assess whether the mean number of units of blood transfused, mean admission $\mathrm{Hb}$ level and mean admission symptom score could explain disagreement between study results. Mean number of units of RBC transfused were reported in twelve studies, mean admission $\mathrm{Hb}$ level were reported in nine studies, mean APACHE II score were reported in eight studies, mean SOFA score were reported in four studies [2-4,42], and mean SAPS II [35] and mean APACHE III score [39] were reported in only one study, respectively. Results of meta-regression failed to identify significant association across studies for mean number of units of RBC transfused (coefficient $-0.1676,95 \% \mathrm{CI},-0.3865$ to 0.0504 ), mean admission $\mathrm{Hb}$ level (coefficient -0.1848, 95\%CI, -0.4343 to 0.0648 ) and mean APACHE II score (coefficient $0.0202,95 \% \mathrm{CI},-0.0569$ to 0.0973 ). In other words, these variables could not explain the disagreement across studies.

e. Blood transfusion may decrease risk of mortality in older patients.

The slope estimate was significant -0.0417 (95\%CI, -0.0680 to -0.0154 ) (Figure S8 in Additional file 7), suggesting that with older age, transfused patients had better chances of survival. This is interesting since age has long been known as a predictor for worse outcomes including mortality. We speculate that this may be due to the following reasons. (1) Older patients and younger patients have different etiology of anemia. Older patients are more likely to have nutritional deficiency, chronic diseases and unexplained anemia [51]. Consequently, older patients and younger patients may differ in disease severity and clinical treatment. (2) Hb level may be a potential explanation. Using World Health Organization (WHO) definition of anemia ( $\mathrm{Hb}$ level $<13 \mathrm{~g} / \mathrm{dL}$ in men and $<12 \mathrm{~g} / \mathrm{dL}$ in women), the corrected annual incidence of anemia increased with age [52], and the study found that even a 'higher' $\mathrm{Hb}$ level was associated with risk of death in older people [53]. Older patients may have different 'optimal' Hb concentrations, a 'mildly low' and 'low-normal' Hb level may be well tolerated in young patients, but not in older people $[54,55]$. Literature on patient's age, survival and blood transfusion is controversial in defining anemia in older people. Although we identified a significant association between mean age of patient and survival, there was no strong evidence to support this view. Further research could explore whether blood transfusion is more effective in improving survival in older patients. 
f. The debate on whether it is beneficial or harmful for RBC transfusion: articles tend to report lower risk effect estimates.

The number of reports concerning such issues has grown fast in recent years, as shown in Figure S7 in Additional file 8. The meta-regression analysis produced a significant effect for publication year. Recent studies are more likely to report relativity lower risk ratios, indicating that $\mathrm{RBC}$ transfusion might have gradually become safer [56]. Safety concerns in RBC transfusion have emerged during the past two decades along with clinical practice changes [57]. The most important change in clinical practice is the recognition that the decision to transfuse should not be driven by a single $\mathrm{Hb}$ threshold, but by the physiologic state of the individual patient, presence of comorbidity, cardiopulmonary physiologic parameters, and evidence of blood loss [56,58]. In our meta-analysis, seven studies from the years 2002 to 2012 had reported average pretransfused $\mathrm{Hb}$ levels, and the mean $\mathrm{Hb}$ levels ranged from $6.6 \mathrm{~g} / \mathrm{dL}$ to $8.6 \mathrm{~g} / \mathrm{dL}$. Meta-regression for pretransfusion $\mathrm{Hb}$ level failed to identify the significance for risk of mortality (coefficient $-0.216,95 \% \mathrm{CI}-0.859$ to 0.428 ).

\section{Limitations}

It should be noted that the present meta-analysis had several limitations. First, all studies included in the meta-analysis were observational studies. Limited by study design, a causal relationship could not be determined. A convincible causal relationship needs further research in large RCTs. Second, limited by our recognition of exact mechanisms of transfusion-related complications, the potential confounders for death were not fully adjusted and may not all be included in our meta-analysis, this may have led to potential risk of bias. Third, the number of studies in subgroup and meta-regression analyses was relativity small, and therefore produced unstable effect estimates. Fourth, our study only focused on mortality within one month, while patients with death after one month of hospitalization may have high risk of transfusion. Finally, publication bias may still exist from unpublished studies, and publications in sources out of our literature search criteria.

\section{Conclusions}

Our systematic review and meta-analysis summarized published literature on the relation between RBC transfusion and in-hospital mortality of ICU patients. We conclude that there is a lack of evidence to support the claim that ICU patients who receive RBC transfusion have an increased risk of in-hospital mortality. In studies that have adjusted for confounders, RBC transfusion did not increase the risk of in-hospital mortality in ICU patients. The review also suggests possible reasons to explain the discrepancies between previous studies. Our finding points to the need to identify risk factors for mortality in patients admitted to the medical ICU to account for all possible confounders for mortality. RCTs are warranted to provide convincible evidence of casual association.

\section{Key messages}

- There was no consistent evidence to link RBC transfusion with mortality in ICU patients.

- In studies that had adjusted for confounders, RBC transfusion was not associated with in-hospital mortality in ICU patients.

- The discrepancies on risk of mortality and RBC transfusion between previous studies may be due to different types of patients, information on leukoreduction, study design and statistical methods, age of patients, and publication year.

\section{Additional files}

Additional file 1: Figure S1. Risk of bias assessment.

Additional file 2: Figure S2. Association between red blood cell transfusion and in-hospital mortality, grouped by type of patient.

Additional file 3: Figure S3. Association between red blood cell transfusion and in-hospital mortality, grouped by outcome measurement.

Additional file 4: Figure S4. Association between red blood cell transfusion and in-hospital mortality, grouped by adjustment for confounding.

Additional file 5: Figure S5. Association between red blood cell transfusion and in-hospital mortality, grouped by leukoreduced usage.

Additional file 6: Figure S6. Funnel plot for assessing publication bias of studies.

Additional file 7: Figure S8. Meta-regression for mortality associated with mean age of patient.

Additional file 8: Figure S7. Meta-regression for mortality associated with published year of article.

\section{Abbreviations}

ALI: acute lung injury; APACHE: acute physiology and chronic health evaluation; ARDS: acute respiratory distress syndrome; Cl: confidence interval; $\mathrm{Hb}$ : hemoglobin; HR: hazard ratio; ICU: intensive care unit; LOS: length of stay; OR: odds ratio; RBC: red blood cell; RCT: randomized controlled trial; RR: relative risk; SAPS II: simplified acute physiology score II; SOFA: sepsis-related organ failure assessment; TRALI: transfusion-related acute lung injury.

\section{Competing interests}

The authors declare that they have no competing interests.

\section{Authors' contributions}

$Y Z, C L, S W$ and $P Y$ carried out the literature search and drafted the manuscript. $Y Z, C L, Y L$ and $L L$ participated in the design of the study and performed the statistical analysis. $Y L, L L$ and PY conceived the study, and participated in the study design and contributed to drafting the manuscript. All authors read and approved the final manuscript. 


\section{Authors' information}

Yi Zheng and Caihong Lu: the first two authors should be regarded as joint first authors.

\section{Author details}

Department of Epidemiology and Biostatistics, School of Public Health, Tongji Medical College, Huazhong University of Science and Technology, 1037 Luoyu Road, Hongshan, Wuhan, China. ${ }^{2}$ Department of ENT department, Union Hospital, Tongji Medical College, Huazhong University of Science and Technology, 1037 Luoyu Road, Hongshan, Wuhan, China.

Received: 4 March 2014 Accepted: 28 August 2014

Published online: 14 November 2014

\section{References}

1. von Ahsen N, Muller C, Serke S, Frei U, Eckardt KU: Important role of nondiagnostic blood loss and blunted erythropoietic response in the anemia of medical intensive care patients. Crit Care Med 1999, 27:2630-2639.

2. Vincent JL, Baron JF, Reinhart K, Gattinoni L, Thijs L, Webb A, Meier-Hellmann A, Nollet G, Peres-Bota D: Anemia and blood transfusion in critically ill patients. JAMA 2002, 288:1499-1507.

3. Corwin HL, Gettinger A, Pearl RG, Fink MP, Levy MM, Abraham E, MacIntyre NR, Shabot MM, Duh MS, Shapiro MJ: The CRIT study: anemia and blood transfusion in the critically ill-current clinical practice in the United States. Crit Care Med 2004, 32:39-52.

4. Park DW, Chun BC, Kwon SS, Yoon YK, Choi WS, Sohn JW, Peck KR, Kim YS, Choi YH, Choi JY, Kim SI, Eom JS, Kim HY, Cheong HJ, Song YG, Choi HJ, Kim JM, Kim MJ: Red blood cell transfusions are associated with lower mortality in patients with severe sepsis and septic shock: a propensity-matched analysis*. Crit Care Med 2012, 40:3140-3145.

5. Walsh TS, Lee RJ, Maciver CR, Garrioch M, Mackirdy F, Binning AR, Cole S, McClelland DB: Anemia during and at discharge from intensive care: the impact of restrictive blood transfusion practice. Intensive Care Med 2006, 32:100-109.

6. Hebert PC, Wells G, Tweeddale M, Martin C, Marshall J, Pham B, Blajchman M, Schweitzer I, Pagliarello G: Does transfusion practice affect mortality in critically ill patients? Transfusion Requirements in Critical Care (TRICC) Investigators and the Canadian Critical Care Trials Group. Am J Respir Crit Care Med 1997, 155:1618-1623.

7. Go AS, Yang J, Ackerson LM, Lepper K, Robbins S, Massie BM, Shlipak MG: Hemoglobin level, chronic kidney disease, and the risks of death and hospitalization in adults with chronic heart failure: the Anemia in Chronic Heart Failure: Outcomes and Resource Utilization (ANCHOR) Study. Circulation 2006, 113:2713-2723.

8. Salisbury AC, Alexander KP, Reid KJ, Masoudi FA, Rathore SS, Wang TY, Bach RG, Marso SP, Spertus JA, Kosiborod M: Incidence, correlates, and outcomes of acute, hospital-acquired anemia in patients with acute myocardial infarction. Circ Cardiovasc Qual Outcomes 2010, 3:337-346.

9. Mehdi U, Toto RD: Anemia, diabetes, and chronic kidney disease. Diabetes Care 2009, 32:1320-1326.

10. Carson JL, Duff A, Poses RM, Berlin JA, Spence RK, Trout R, Noveck H, Strom BL: Effect of anaemia and cardiovascular disease on surgical mortality and morbidity. Lancet 1996, 348:1055-1060.

11. Conrad SA, Dietrich KA, Hebert CA, Romero MD: Effect of red cell transfusion on oxygen consumption following fluid resuscitation in septic shock. Circ Shock 1990, 31:419-429.

12. Marik PE, Sibbald WJ: Effect of stored-blood transfusion on oxygen delivery in patients with sepsis. JAMA 1993, 269:3024-3029.

13. Mohsenifar Z, Ross DJ: Oxygen consumption is independent of changes in oxygen delivery in severe adult respiratory distress syndrome. Am Rev Respir Dis 1992, 145:978-979.

14. Apstein CS, Dennis RC, Briggs L, Vogel WM, Frazer J, Valeri CR: Effect of erythrocyte storage and oxyhemoglobin affinity changes on cardiac function. Am J Physiol 1985, 248:H508-H515.

15. Wolfe LC, Byrne AM, LuX SE: Molecular defect in the membrane skeleton of blood bank-stored red cells. Abnormal spectrin-protein 4.1-actin complex formation. J Clin Invest 1986, 78:1681-1686.

16. Blumberg N, Heal JM: Immunomodulation by blood transfusion: an evolving scientific and clinical challenge. Am J Med 1996, 101:299-308.
17. Linda CS, Dennis CD, Ronald JF, Gerson Greenburg A, Chantal RH, Dennis FL, Russell KL, Ellison CP, Randall SP, Andrew DR, Richard BW, Steven HW, John FZ: Practice guidelines for blood component therapy: a report by the American Society of Anesthesiologists Task Force on Blood Component Therapy. Anesthesiology 1996, 84:732-747.

18. Cermakova Z, Simetka O, Koristka M: Transfusion-related acute lung injury (TRALI) - review. Ceska Gynekol 2013, 78:211-215.

19. Taylor RW, O'Brien J, Trottier SJ, Manganaro L, Cytron M, Lesko MF, Arnzen K, Cappadoro C, Fu M, Plisco MS, Sadaka FG, Veremakis C: Red blood cell transfusions and nosocomial infections in critically ill patients. Crit Care Med 2006, 34:2302-2308. quiz 2309.

20. Marik PE, Corwin HL: Efficacy of red blood cell transfusion in the critically ill: a systematic review of the literature. Crit Care Med 2008, 36:2667-2674.

21. Sakr Y, Lobo S, Knuepfer S, Esser E, Bauer M, Settmacher U, Barz D, Reinhart K: Anemia and blood transfusion in a surgical intensive care unit. Crit Care 2010, 14:R92.

22. van de Watering LM, Hermans J, Houbiers JG, van den Broek PJ, Bouter H, Boer F, Harvey MS, Huysmans HA, Brand A: Beneficial effects of leukocyte depletion of transfused blood on postoperative complications in patients undergoing cardiac surgery: a randomized clinical trial. Circulation 1998, 97:562-568.

23. Hebert PC, Wells G, Marshall J, Martin C, Tweeddale M, Pagliarello G, Blajchman M: Transfusion requirements in critical care. A pilot study. Canadian Critical Care Trials Group. JAMA 1995, 273:1439-1444.

24. Basran S, Frumento RJ, Cohen A, Lee S, Du Y, Nishanian E, Kaplan HS, Stafford-Smith M, Bennett-Guerrero E: The association between duration of storage of transfused red blood cells and morbidity and mortality after reoperative cardiac surgery. Anesth Analg 2006, 103:15-20. Table of contents.

25. Eikelboom JW, Cook RJ, Liu Y, Heddle NM: Duration of red cell storage before transfusion and in-hospital mortality. Am Heart J 2010, 159:737-743. e1

26. Hebert PC, Wells G, Blajchman MA, Marshall J, Martin C, Pagliarello G, Tweeddale M, Schweitzer I, Yetisir E, Transfusion Requirements in Critical Care Investigators, Canadian Critical Care Trials Group: A multicenter, randomized, controlled clinical trial of transfusion requirements in critical care. N Engl J Med 1999, 340:409-417.

27. von Elm E, Altman DG, Egger M, Pocock SJ, Gotzsche PC, Vandenbroucke JP: The Strengthening the Reporting of Observational Studies in Epidemiology (STROBE) statement: guidelines for reporting observational studies. J Clin Epidemiol 2008, 61:344-349.

28. Borenstein M, Hedges L, Higgins J, Rothstein $\mathrm{H}$ : Comprehensive Meta-Analysis Version 2. Biostat: Englewood, NJ; 2005.

29. Zhang J, Yu KF: What's the relative risk? A method of correcting the odds ratio in cohort studies of common outcomes. JAMA 1998, 280:1690-1691.

30. McNutt $L A$, Wu $C$, Xue $X$, Hafner JP: Estimating the relative risk in cohort studies and clinical trials of common outcomes. Am J Epidemio/ 2003, 157:940-943.

31. Croce MA, Tolley EA, Claridge JA, Fabian TC: Transfusions result in pulmonary morbidity and death after a moderate degree of injury. J Trauma 2005, 59:19-23. discussion 23-24.

32. Robinson WP 3rd, Ahn J, Stiffler A, Rutherford EJ, Hurd H, Zarzaur BL, Baker CC, Meyer AA, Rich PB: Blood transfusion is an independent predictor of increased mortality in nonoperatively managed blunt hepatic and splenic injuries. J Trauma 2005, 58:437-444. discussion 444-435.

33. Netzer G, Shah CV, Iwashyna TJ, Lanken PN, Finkel B, Fuchs B, Guo W, Christie JD: Association of RBC transfusion with mortality in patients with acute lung injury. Chest 2007, 132:1116-1123.

34. Ruttinger D, Wolf H, Kuchenhoff H, Jauch KW, Hartl WH: Red cell transfusion: an essential factor for patient prognosis in surgical critical illness? Shock 2007, 28:165-171.

35. Vincent JL, Sakr Y, Sprung C, Harboe S, Damas P: Are blood transfusions associated with greater mortality rates? Results of the Sepsis Occurrence in Acutely III Patients study. Anesthesiology 2008, 108:31-39.

36. Bochicchio GV, Napolitano L, Joshi M, Bochicchio K, Meyer W, Scalea TM: Outcome analysis of blood product transfusion in trauma patients: a prospective, risk-adjusted study. World J Surg 2008, 32:2185-2189.

37. Bursi F, Barbieri A, Politi L, Di Girolamo A, Malagoli A, Grimaldi T, Rumolo A Busani S, Girardis M, Jaffe AS, Modena MG: Perioperative red blood cell transfusion and outcome in stable patients after elective major vascular surgery. Eur J Vasc Endovasc Surg 2009, 37:311-318. 
38. Engoren M, Arslanian-Engoren C: Long-term survival in the intensive care unit after erythrocyte blood transfusion. Am J Crit Care 2009, 18:124-131. quiz 132.

39. Parsons EC, Hough CL, Seymour CW, Cooke CR, Rubenfeld GD, Watkins TR: Red blood cell transfusion and outcomes in patients with acute lung injury, sepsis and shock. Crit Care 2011, 15:R221.

40. Sheth KN, Gilson AJ, Chang Y, Kumar MA, Rahman RM, Rost NS, Schwab K, Cortellini L, Goldstein JN, Smith EE, Greenberg SM, Rosand J: Packed red blood cell transfusion and decreased mortality in intracerebral hemorrhage. Neurosurgery 2011, 68:1286-1292.

41. Brophy DF, Harpe SE, Carl DE, Brophy GM: An epidemiological study of anemia and renal dysfunction in patients admitted to ICUs across the United States. Anemia 2012, 2012:938140.

42. Silva Junior JM, Rezende E, Amendola CP, Tomita R, Torres D, Ferrari MT, Toledo DO, Oliveira AM, Marques JA: Red blood cell transfusions worsen the outcomes even in critically ill patients undergoing a restrictive transfusion strategy. Sao Paulo Med J 2012, 130:77-83.

43. Sekhon MS, McLean N, Henderson WR, Chittock DR, Griesdale DE: Association of hemoglobin concentration and mortality in critically ill patients with severe traumatic brain injury. Crit Care 2012, 16:R128.

44. Weinberg JA, McGwin G Jr, Griffin RL, Huynh VQ, Cherry SA 3rd, Marques MB, Reiff DA, Kerby JD, Rue LW 3rd: Age of transfused blood: an independent predictor of mortality despite universal leukoreduction. J Trauma 2008, 65:279-282. discussion 282-274.

45. Lelubre C, Vincent $\mathrm{J}$ : Relationship between red cell storage duration and outcomes in adults receiving red cell transfusions: a systematic review. Crit Care 2013, 17:R66.

46. Vamvakas EC, Blajchman MA: Transfusion-related immunomodulation (TRIM): an update. Blood Rev 2007, 21:327-348.

47. Shander A: Anemia in the critically ill. Crit Care Clin 2004, 20:159-178.

48. Bilgin YM, van de Watering LM, Brand A: Clinical effects of leucoreduction of blood transfusions. Neth J Med 2011, 69:441-450.

49. Green MS, Symons MJ: A comparison of the logistic risk function and the proportional hazards model in prospective epidemiologic studies. J Chronic Dis 1983, 36:715-723.

50. Cepeda MS, Boston R, Farrar JT, Strom BL: Comparison of logistic regression versus propensity score when the number of events is low and there are multiple confounders. Am J Epidemiol 2003, 158:280-287.

51. Bross MH, Soch K, Smith-Knuppel T: Anemia in older persons. Am Fam Physician 2010, 82:480-487.

52. Ania BJ, Suman VJ, Fairbanks VF, Rademacher DM, Melton $L J$ 3rd: Incidence of anemia in older people: an epidemiologic study in a well defined population. J Am Geriatr Soc 1997, 45:825-831.

53. Zakai NA, Katz R, Hirsch C, Shlipak MG, Chaves PH, Newman AB, Cushman $\mathrm{M}$ : A prospective study of anemia status, hemoglobin concentration, and mortality in an elderly cohort: the Cardiovascular Health Study. Arch Intern Med 2005, 165:2214-2220.

54. Chaves PH, Ashar B, Guralnik JM, Fried LP: Looking at the relationship between hemoglobin concentration and prevalent mobility difficulty in older women. Should the criteria currently used to define anemia in older people be reevaluated? J Am Geriatr Soc 2002, 50:1257-1264.

55. Milman N, Pedersen AN, Ovesen L, Schroll M: Hemoglobin concentrations in 358 apparently healthy 80 -year-old Danish men and women. Should the reference interval be adjusted for age? Aging Clin Exp Res 2008, 20:8-14.

56. Napolitano LM, Kurek S, Luchette FA, Anderson GL, Bard MR, Bromberg W, Chiu WC, Cipolle MD, Clancy KD, Diebel L, Hoff WS, Hughes KM, Munshi I, Nayduch D, Sandhu R, Yelon JA, Corwin HL, Barie PS, Tisherman SA, Hebert PC: Clinical practice guideline: red blood cell transfusion in adult trauma and critical care. J Trauma 2009, 67:1439-1442.

57. Lelubre C, Vincent $J$ : Red blood cell transfusion in the critically ill patient. Ann Intensive Care 2011, 1:43.

58. Hare GM, Baker JE, Mazer CD: Perioperative management of acute and chronic anemia: has the pendulum swung too far? Can J Anaesth 2009, 56:183-189.

\section{doi:10.1186/s13054-014-0515-z}

Cite this article as: Zheng et al:: Association of red blood cell transfusion and in-hospital mortality in patients admitted to the intensive care unit: a systematic review and meta-analysis. Critical Care 2014 18:515.

\section{Submit your next manuscript to BioMed Central and take full advantage of:}

- Convenient online submission

- Thorough peer review

- No space constraints or color figure charges

- Immediate publication on acceptance

- Inclusion in PubMed, CAS, Scopus and Google Scholar

- Research which is freely available for redistribution 